\title{
AS FONTES COMO INSTRUMENTO DE LEGITIMAÇÃO DO PODER RÉGIO CASTELHANO (SÉCULO XIII)
}

\section{Rafael de Mesquita Diehl ${ }^{1}$}

Podemos observar na história política medieval, uma relação sempre existente entre prática e teoria, embora não o seja de uma maneira absoluta. A teoria não condiciona totalmente a prática, mas a influencia. Da mesma forma, o contexto histórico também exerce influência sobre as construções teóricas. No século XIII, um fator importante dos acontecimentos políticos é o processo de fortalecimento do poder régio. Este processo foi levado a cabo através do "jogo" político das monarquias feudais, i.e., as relações entre o rei, a nobreza e a Igreja. Na Península Ibérica, essas relações ocorrem sob um contexto específico: o da Reconquista. Não obstante, além dos conflitos contra os reinos mouriscos, os próprios reinos cristãos peninsulares encontravam-se em situações de eventuais conflitos.

Durante o período mais significativo da Reconquista em Castela, ou seja, durante o reinado de Fernando III, o Santo (12171252) que se inicia um processo significativo de fortalecimento do poder régio. Neste momento, ocorria também uma elaboração teórica que visava legitimar e fortalecer a figura do rei, através de uma identificação, uma idéia de unidade do reino em torno do rei. Essa elaboração teórica é feita de maneira indireta, através das Crônicas, onde o rei é mostrado como o principal personagem da História.

O objetivo desse artigo é analisar os processos acima descritos nos relatos do reinado de Fernando III contidos na Primera Crónica General de España que mandó componer Alfonso el Sabio y se

\footnotetext{
${ }^{1}$ Graduando do $6^{\circ}$ período do curso de Licenciatura e Bacharelado em História da Universidade Federal do Paraná (UFPR) e membro do Núcleo de Estudos Mediterrâneos (NEMED).
} 
continuaba bajo Sancho IV en $1289 .^{2}$ Como estes relatos são constituídos em parte por escritos originais da dita crônica e por transcrições dos relatos do Arcebispo de Toledo, Dom Rodrigo Jiménez de Rada, nos debruçaremos sobre ambos os estilos cronísticos. O texto será estruturado em três partes. Primeiramente, apresentaremos uma breve contextualização do período e em seguida, trataremos da Crônica. Por fim analisaremos o relato buscando ver a construção teórica de legitimação e fortalecimento do poder régio implícita no texto. ${ }^{3}$

A transição do século XII para o XIII denota um período de instabilidade política na Península Ibérica. Nele observamos a ascensão e queda do Califado Almôada, a fragmentação de $\mathrm{Al}$ Andaluz, as inconstantes alianças entre os reinos cristãos peninsulares e o crescimento do poder e da influência do reino de Castela na Península, frente ao poderio do reino de Leão. Todos esses fatores são indícios da dita instabilidade política ibérica. ${ }^{4}$ Nosso enfoque aqui deter-se-á mais sobre as relações entre os Reinos de Leão e Castela após a morte de Henrique I de Castela em 1217.

Como foi fito acima, após a vitória cristã na Batalha das Navas de Tolosa (1212), onde combateram os reis de Castela, Aragão e Navarra contra o Califa Almôada, inicia-se o declínio do poderio

${ }^{2}$ Usaremos a edição de Ramón Menendez-Pidal de 1955.

${ }^{3}$ Para as considerações contextuais, usaremos principalmente o estudo de Derek W. Lomax sobre a Reconquista e o estudo de José-Luis Martín sobre as relações de Afonso IX de Leão com o reino de Castela. Com relação às Crônicas nos basearemos nos estudos de Leonardo Funes sobre as crônicas afonsinas e no estudo de Lomax sobre as crônicas do arcebispo Rodrigo de Toledo. Para tecermos considerações acerca do poder régio nas Crônicas, usaremos a obra de Jenaro Costas sobre a imagem de Fernando III nas crônicas.

${ }^{4}$ Não nos deteremos muito em todos os acontecimentos políticos dessa passagem do século XII ao XIII na Península Ibérica. Para mais detalhes sobre isso vide DIEHL, Rafael de Mesquita. A Reconquista Ibérica no Século XIII. Material didático produzido em CD-ROM para o Laboratório de História Antiga e Medieval do Núcleo de Estudos Mediterrâneos (NEMED), 2007; LOMAX, Derek W. La Reconquista. Barcelona: Editorial Crítica, 1984. pp. 107-168. 
Almoâda sobre Al-Andalus, sendo que esse fragmenta-se novamente em várias taifas, reinos autônomos. Também podemos observar algumas mudanças no plano político. O reino de Aragão, após sofrer derrotas para os franceses na Cruzada Albigense, acaba por envolver-se definitivamente no processo de Reconquista, buscando um novo eixo de expansão e atuação política. $\mathrm{O}$ reino de Castela assume uma posição de destaque no cenário político ibérico, rivalizando com o reino de Leão. ${ }^{5}$

É também característico também desse período pós-Navas de Tolosa uma breve estagnação do processo de Reconquista, visto as disputas entre os reinos de Leão e Castela como também os próprios conflitos internos entre os castelhanos. Focaremos nossa análise no caso Castelhano, como já explicitamos anteriormente. No ano de 1214, com a morte do rei Afonso VIII de Castela (o vencedor da batalha de Navas de Tolosa), assume o trono seu filho Henrique I que ainda tinha pouca idade. Desta forma, a tutela do menino é disputada pelo Conde de Lara, Dom Álvaro Nuñez e pela irmã do herdeiro, Berengária. Durante esse período, a reconquista é levada a cabo pelas ordens militares, visto que os reinos estavam em conflito.

Em 1217, morre o rei Henrique em um acidente. Berengária, então, assume o trono castelhano e em seguida renuncia ao mesmo em favor do filho, o infante Fernando. ${ }^{6}$ Este assume o reino e é jurado pelas cortes de Valladolid. Entretanto, tal sucessão não foi

${ }^{5}$ LOMAX, Derek W. La Reconquista. pp. 169-175.

${ }^{6}$ Fernando era filho de Afonso IX de Leão e de Berengária, filha de Afonso VIII de Castela. Em 11196, devido ao conflitos de Leão com outros reinos cristãos ibéricos, o papa Celetino III ordenou ao arcebispo Martin de Toledo que excomungasse Afonso IX por usar hostes muçulmanas para atacar cristãos, oferecendo indulgências a quem combatesse o rei leonês e liberando os leoneses da obediência a seu rei. Afonso IX dirigiu-se a Sevilha para solicitar auxílio do Califa, mas os reis de Portugal, Castela e Aragão obrigaram o rei leonês a firmar a paz com Castela, mediante o casamento do mesmo com a filha de Afonso VIII, Berengária. Tal casamento, contudo, foi mantido somente até o nascimento de um herdeiro, tendo sido considerado nulo posteriormente pelo papa Inocêncio III, pelo fator de consangüinidade, o que tornava um matrimônio nulo, segundo os cânones eclesiásticos. Para tanto, vide LOMAX, Derek W. Op. cit. pp.159-160. 
reconhecida pelo rei Afonso IX de Leão e pelos condes de Lara. Os condes de Lara invadiram o território castelhano, apoiados pelo rei leonês. A partir daí já percebe-se uma dificuldade do novo rei castelhano de manter sua legitimidade, visto não ser reconhecido por um dos principais reinos da Cristandade ibérica, bem como pelos condes de Lara, que nominalmente seriam vassalos do monarca de Castela. O rei Fernando, contudo, consegue aprisionar os condes de Lara e obriga-los a devolver todas as fortalezas que estivessem sob o poder dos ditos condes.

Castela é invadida novamente, pelas hostes de Afonso IX de Leão. Os prelados e nobres de ambos os reinos, contudo, conseguem firmar uma trégua. Após a morte dos condes de Lara, um novo tratado de paz é firmado, imputando pena de excomunhão para quem o violasse. Analisemos brevemente agora as possíveis razões do conflito entre Leão e Castela. Os cronistas Rodrigo de Toledo e Juan Gil relatam que no início de seu reinado, Afonso IX de Leão teria se feito vassalo de Afonso VIII de Castela, recebendo deste o cíngulo de cavaleiro. Segundo o arcebispo toledano, tal fato teria sido considerado para o rei leonês uma humilhação, o que o teria induzido a buscar uma aliança com Portugal contra Castela, através do casamento com Teresa, filha do rei português. Contudo, segundo José-Luis Martín, o conflito se devia à disputa entre Leão e Castela pelo território da Extremadura. A região da Extremadura estava inserida em uma querela de jurisdições eclesiásticas. O controle da dita região era disputado pelos arcebispados de Mérida-Santiago de Compostela, localizado em território leonês, e Toledo, localizado em território castelhano. Desde 1160, castelhanos, leoneses e os muçulmanos guerreavam pelo território da Extremadura. ${ }^{8}$

A busca por certa estabilidade por Castela evidencia-se no matrimônio celebrado entre Fernando III e Beatriz, filha de Filipe da

\footnotetext{
${ }^{7}$ LAFUNETE, Modesto. Historia de España. Tomo 4. Barcelona: Montanery y Simon, S. A., 1930. pp. 31-33.

${ }^{8}$ MARTÍN, José-Luis. Alfonso IX y sus relaciones con Castilla. In: Espacio, Tiempo y Forma. Serie III. Historia Medieval, t. 7, 1994, pp. 11-31. pp. 17-20.
} 
Suábia, em 1219. O fato de muitos casamentos entre os príncipes ibéricos terem sido nulos devido à consangüinidade existente entre as diversas casas régias peninsulares teria, segundo Modesto Lafuente, o motivo pela qual Berengária de Castela teria procurado para o filho uma aliança matrimonial mais estável com uma casa nobiliárquica extra-peninsular. ${ }^{9}$

Apesar de algumas pequenas revoltas nobiliárquicas entre os anos de 1219 a 1222, Fernando III consegue relativa estabilidade, o que the permite iniciar, a partir de 1224, suas incursões nos territórios pertencentes aos reinos mouriscos de Al-Andalus. Tais incursões seguem-se todos os anos, comandadas pelo rei, após passar os invernos em Toledo. Estas expedições são temporariamente interrompidas no ano de 1230, devido à morte de Afonso IX de Leão. Fernando dirige-se à Leão para tomar posse do reino.

A situação sucessória de Afonso IX, contudo, era complexa. Por um lado, o testamento do finado monarca leonês determinava que as herdeiras deveriam ser as infantas Sancha e Dulce, filhas de seu casamento com Teresa de Portugal. Por outro lado, Fernando havia sido declarado sucessor por meio de juramento, em ocasião de seu nascimento, pelo seu pai e pelas cortes de Leão, decisão essa reconhecida e confirmada pelos prelados do reino e pelo papa Honório III. Berengária negocia um acordo com as infantas Sancha e Dulce, na qual Fernando III seria reconhecido como rei de Leão enquanto as ditas infantas receberiam uma pensão para seus sustentos. Apesar da oposição de alguns nobres, Fernando recebe o apoio do arcebispo de Leão e da população, conseguindo dessa forma ser coroado como rei de Leão.

Desta forma, tendo unificado em sua pessoa os reinos de Castela e Leão, Fernando III adquire maio estabilidade política, o que é adquirido também mediante tratados com outros reinos, como

\footnotetext{
${ }^{9}$ LAFUENTE, Modesto. Op cit. pp. 31-33.

${ }^{10}$ LAFUENTE, Modesto. Op. cit. pp. 33-39; MARTÍN, José-Luis. Op. Cit. pp. 2223.
} 
o Tratado de Sabugal, firmado com Portugal em 1231, e os diversos tratados firmados com o reino de Aragão. ${ }^{11}$ Tais tratados visavam manter a paz entre os reinos e definir os eixos de expansão políticoterritorial de cada reino. Assim, Fernando III pôde concentrar-se em seu projeto de Reconquista dos territórios em Al-Andalus, aproveitando-se das divergências internas entre as diversas taifas mouriscas. Desta forma, inicia-se o período denominado por Lomax de "Grande Reconquista", caracterizado pelas conquistas de Fernando III e Jaime I, sendo que no final do século XIII, restava apenas o reino mourisco de Granada, que prestara vassalagem à Castela.

Passemos agora a analisar a questão das Crônicas. O estilo cronístico em inícios do século XIII preserva o modelo tradicional, utilizando a língua latina. Na Península Ibérica temos nesse período como exemplo a Historia de rebus Hispaniae (também conhecida como Historia Gothica), de autoria do arcebispo de Toledo, Rodrigo Jiménez de Rada (O Toledano). Já na segunda metade do século XIII, observamos mudanças no gênero cronístico, principalmente através do estilo afonsino que inicia a utilização da língua romance, ao invés do latim. Neste sentido, temos a Primera Crónica General de España que mando componer Afonso el Sábio y se continuaba bajo Sancho IV en 1289 (Que constitui a Estoria de España, elaborada na corte de Afonso X de Castela e Leão, ampliada e continuada por seu filho Sancho IV) e a General Estoria, também produzida pela corte de Afonso X.

A primeira Crônica que analisaremos, é a do arcebispo Rodrigo, Historia de rebus Hispaniae. ${ }^{12}$ Este escrito já se diferencia um pouco do modelo tradicional de crônica universal, visto que

11 Castela realizou vários tratados neste sentido com Aragão, como Tudilén, Cazorla e Almizra, sendo que este último fora firmado entre o infante Afonso (herdeiro de Fernando III) e Jaime I de Aragão em 1244. Para tanto, vide: CORTÁZAR, José Angel Garcia de. Historia de España. Vol II: La Época Medieval. Madrid: Alianza Universidad, 1985. p. 171.

${ }^{12}$ Os trechos que analisaremos dessa obra são os transcritos na Primera Crónica General. 
centra-se na história peninsular. Esta obra foi encomendada pelo rei São Fernando, mas como resposta à novas necessidades políticas e sociais, conforme assinala Lomax. Segundo o autor, a obra do Toledano visava criar uma idéia de unidade, haja vista o fato de que após as conquistas em Al-Andalus, São Fernando havia se tornado senhor de vários reinos distintos. Estes reinos eram, naturalmente, diferentes entre si. Para tanto, o arcebispo de Toledo cria, através do seu relato, um passado comum, que liga os povos ibéricos aos godos, que dominaram a Península antes da conquista pelos muçulmanos no século VIII. Dessa forma, esses povos teriam o destino de "reconquistarem" a península dos muçulmanos. Contudo, Lomax relembra que este "povo visigodo" não identificava-se com a maioria dos povos ibéricos, mas com a minoria politizada, a realeza, representada pela urbe regia de Toledo.

A Historia Gothica narra, em seu livro IX desde a morte de Henrique I de Castela até o ano de 1243, período em que foi acabada. Tal período corresponde à parte do reinado de Fernando III. A crônica do Toledano, embora enalteça a figura de Fernando III, dá mais destaque às figuras de seu avô Afonso VIII de Castela e de sua mãe, Berengária. O pouco destaque dado à Fernando pode ser devido a alguns problemas deste com a Sé Toledana, segundo aponta Lomax. Segundo o autor, o objetivo da Crônica parece ser mais o de enaltecer a Sé de Toledo como um referencial de unidade. $^{13}$

A Primera Crónica General, por outro lado, fora escrita pela corte de Afonso X de Castela e Leão ${ }^{14}$ e já apresentava uma visão

${ }^{13}$ LOMAX, Derek W. Rodrigo Jiménez de Rada como Historiador. In: AHI, Actas $V$. Centro Virtual Cervantes, 1974. pp. 588-589.

${ }^{14}$ Os estudos mais recentes sobre as crônicas afonsinas tem questionado sobre o caráter legitimamente afonsino da Primera Crónica General à partir do capítulo 616. Levantam a possibilidade de ter sido acréscimos posteriores, muito provavelmente feitos pela corte de Sancho IV. Para uma maior compreensão da questão e do estilo cronístico afonsino em geral, vide FUNES, Leonardo. De Alfonso el Sabio al Canciller Ayala: variaçones del relato histórico (Conclusiones del seminario dictado em la Universidad de Buenos Aires, agosto-noviembre de 
mais clara no sentido de enaltecer a monarquia Castelhana. Ela relata além dos acontecimentos contidos nos relatos do Toledano (e que muitas vezes são cópias e transcrições de trechos de sua obra) e em outros cronistas, os anos finais do reinado de Fernando, entre a tomada de Córdoba em 1236 à sua morte em 1252. Nessa Crônica é característica também um maior destaque à figura de Fernando III, posto que este torna-se também um referencial de legitimidade para os monarcas que o sucedem. Isto pode induzir, segundo Jenaro Costas, um próprio desejo de Afonso $\mathrm{X}$ de dar um maior protagonismo ao seu pai Fernando no relato cronístico. ${ }^{15}$ Outra novidade da escrita afonsina é seu direcionamento visando também a um público não-letrado, embora ainda seja influenciada pela tradição literária latina. ${ }^{16}$

A Primera Crónica General busca também ligar a monarquia castelhana ao passado romano imperial, o que poderia refletir, segundo Fraker, os interesses de Afonso X em herdar o trono do Sacro Império Romano. ${ }^{17}$ Para Funes, contudo, a principal função do texto não era legitimar as pretensões imperiais, mas "buscar um consenso mediante uma percepção dos atos políticos do rei". ${ }^{18}$ Para Inês Fernández-Ordónez, o imperium é a base das crônicas afonsinas, sendo que o relato organiza-se sob a forma de uma sucessão de senhorios. Interessante observar, contudo, que, pelo que demonstra a autora, não são mencionados os senhorios dos árabes

2002).

Texto

digitaliado

em:

http://parnaseo.uv.es/Memorabilia/Memorabilia7/Funes/Funes.htm. Acesso em 26 de agosto de 2008, às 16h e 14 min; FUNES, Leonardo. Nuevas y Viejas Lecturas de la Historiografia Alfonsí. In: INCIPIT. Volume XVII, Buenos Aires: Seminario de Edición y Crítica textual, 1997, pp. 255-273; e FUNES, Leonardo. Um Nuevo avance e el conocimiento de la Historiografia Alfonsí. In: INCIPIT. Volume XII, Buenos Aires: Seminario de Edición y Crítica textual, 1992, pp. 209-221.

${ }^{15}$ COSTAS RODRÍGUEZ, Jenaro. Fernando III a través de las Crónicas Medievales. Zamora: Exmo. Ayuntamiento de Zamora y Centro de la UNED de Zamora, 2001. p.26.

${ }^{16}$ FUNES, Leonardo. Nuevas y viejas lecturas de la Historiografia Alfonsí. p. 257.

${ }^{17}$ Idem, Ibidem, p. 258-261.

${ }^{18}$ Ibid. p. 262. 
(considerados invasores) nem dos demais reinos hispânicos (Castela pretende-se herdeira única do reino visigodo). ${ }^{19}$ Nesse sentido podese, conforme Fernández-Ordoñéz, "conceber a história como uma sucessão de reinados ou poderios terrenais". ${ }^{20}$ A Crônica não seria então protagonizada pelos povos que dominaram a Península, mas pelos senhores que exerceram imperium sobre ela, tratando-se assim de uma história de príncipes para príncipes. ${ }^{21}$ Por fim, Funes também considera importante a função da cronologia, que através da noção de continuidade daria embasamento para o senhorio. ${ }^{22}$

Se voltarmos ao contexto do reinado de Fernando III, perceberemos algumas situações de maior instabilidade em que se fizeram necessárias uma série de medidas para buscar a legitimação e estagnação do poder do monarca. Filho de um matrimônio nulo, a legitimidade da sucessão hereditária de Fernando poderia sofrer questionamentos. É nesse sentido que os relatos do Toledano enfatizam o papel da rainha e mãe Berengária, bem como relatam o reconhecimento da legitimidade de Fernando pelas cortes de Valladolid:

Et alli ante toda la gent recibio la reyna donna Berenguella de todos otrossi el regno por suyo, como heredera linda quel deuie auer por natura et por derecho; et alli luego otrossi ante todos, dio ella luego el regno a su fijo el rey don Fernando.

[...] et pues quel otorgaran por su rey yl reçibieron por su sennor, alli em aquel logar mismo, em Sancta Maria de Valladolit, fizieronle omenage, et yuraronle quel guardassen bien et lealmientre la lealtad que es deuida a rey. (PCG, capítulo 1029). ${ }^{23}$

${ }^{19}$ FUNES, Leonardo. Un Nuevo avance em el conocimiento de la Historiografia Alfonsí. pp. 210-211.

${ }^{20}$ FERNÁNDEZ-ORDOÑÉZ, Inês. Las Estórias de Alfonso el Sabio. Madrid: Istmo, 1992. p. 38. Citado em: FUNES, Leonardo. Un Nuevo anance..., p. 211.

${ }^{21}$ Ibid.p. 212.

${ }^{22}$ Ibid. p. 213.

23 Primera Crónica General que mando componer Alfonso el Sabio y se continuaba bajo Sancho IV em 1289. Edição de MENÉNDEZ-PIDAL, Ramón. Madrid: Editorial Gredos, 1955. p. 714. 
Por ocasião da querela sucessória pelo reino de Leão, onde novamente há uma instabilidade de legitimidade, a Crônica constrói uma legitimidade pautada no apoio dos prelados e nobres leoneses durante a entrada de Fernando na cidade de Leão:

Et toda la clerezia et la caualleria et el otro pueblo, todos muy alegres com su rey Don Fernando, et de entonces, de alli adelante, fue este rrey Don Fernando em vno llamado ygualmientre: 'rey de Castiella et de Leon', los dos rregnos que el enredo lindamiente de padre et de madre. (PCG, capítulo 1039). ${ }^{24}$

Por fim, encontramos no relato da morte de Fernando uma construção de legitimidade baseada no elo entre pai e filho, ao observarmos os conselhos que Fernando dá ao filho primogênito, Afonso. Tais palavras, segundo Jenaro Costas, seriam como um "testamento político":

Fijo, rico fincas de tierra et de muchos buenos vassalos, mas que rey que en la cristandad ssea; punna en fazer bien et ser bueno, ca bien as con que." "Ssennor te dexo de toda la tierra de la mar aca, que los moros del rey Don Rodrigo de Espanna ganado ovieron; et em tu sennorio finca toda: la uma conquerida, la otra tributada. Sy la en este estado en que te la yo dexo sopieras guardar, eres tan bueno rey como yo; et si ganares por ti mas, eres meior que yo; et si desto menguas, non eres tan bueno como yo. (PCG, capítulo 1132). ${ }^{25}$

Soam curiosas essas palavras atribuídas pela crônica afonsina ao finado rei, onde o reino e suas conseqüentes conquistas são ligados ao passado visigodo do rei Rodrigo. A idéia de continuidade e de passado legitimador, como vemos, aparece aqui de forma significativa.

Parece claro, que o saber histórico produzido nesse contexto está intimamente ligado aos acontecimentos políticos. Recordemos que o processo de Reconquista de Fernando III, na prática fortaleceu e centralizou o poder régio castelhano, haja visto que as incursões em territórios muçulmanos fora sempre organizada pelo rei, e então,

\footnotetext{
${ }^{24}$ Ibid. p. 723.

${ }^{25}$ Ibid, p. $772-773$.
} 
ao mesmo tempo que o rei legitima a função guerreira de sua nobreza ele exerce sobre ela um maior controle. Essa centralização também evidencia no fato de que compete ao mesmo dividir os novos territórios conquistados entre os nobres e também é incumbência exclusiva sua a concessão de fueros para as cidades conquistadas.

Se na passagem do século XII para o XIII, as disputas entre os reinos ibéricos poderiam ser um entrave para a centralização política, durante o reinado de Fernando III este já não é mais um fator de instabilidade, haja vista que o dito rei castelhano realizou alianças e tratados com os demais reinos. A união definitiva dos reinos de Castela e Leão na pessoa de Fernando também contribuiu para uma preponderância do reino castelhano sobre a península. Por fim, consegue-se a estabilidade do reino deslocando-se o conflito para o âmbito externo, ou seja, o combate contra o "infiel". A participação da Igreja torna-se também importante, visto que à mesma interessava a estabilidade no ambiente peninsular, já que este era uma das fronteiras da Cristandade. Assim, vemos que o rei constrói o fortalecimento do seu poder com base em suas relações com a Igreja e a Nobreza, bem como com demais reinos.

Embora a questão ainda não esteja concluída, podemos aferir por tudo o que foi aqui exposto, que as crônicas acabaram fortalecendo a legitimidade do poder régio castelhano por meio de uma construção teórica e política que buscava no rei um referencial de unidade. A presente construção, embora buscasse responder à questões de seu tempo, busca no passado as idéias de continuidade e legitimidade histórica, através das fontes dos saberes e das tradições.

\section{BIBLIOGRAFIA}

Primera Crónica General que mando componer Alfonso el Sabio y se continuaba bajo Sancho IV em 1289. Edição de MENÉNDEZPIDAL, Ramón. Madrid: Editorial Gredos, 1955. 
CORTÁZAR, José Angel Garcia de. Historia de España. Vol II: La Época Medieval. Madrid: Alianza Universidad, 1985.

COSTAS RODRÍGUEZ, Jenaro. Fernando III a través de las Crónicas Medievales. Zamora: Exmo. Ayuntamiento de Zamora y Centro de la UNED de Zamora, 2001.

FUNES, Leonardo. De Alfonso el Sabio al Canciller Ayala: variaçones del relato histórico (Conclusiones del seminario dictado em la Universidad de Buenos Aires, agosto-noviembre de 2002). Texto digitaliado em: http://parnaseo.uv.es/Memorabilia/Memorabilia7/Funes/Funes.htm. Acesso em 26 de agosto de 2008, às $16 \mathrm{~h}$ e $14 \mathrm{~min}$.

FUNES, Leonardo. Nuevas y Viejas Lecturas de la Historiografia Alfonsí. In: INCIPIT. Volume XVII, Buenos Aires: Seminario de Edición y Crítica textual, 1997.

. Um Nuevo avance e el conocimiento de la Historiografia Alfonsí. In: INCIPIT. Volume XII, Buenos Aires: Seminario de Edición y Crítica textual, 1992.

LAFUNETE, Modesto. Historia de España. Tomo 4. Barcelona: Montanery y Simon, S. A., 1930.

LOMAX, Derek W. La Reconquista. Barcelona: Editorial Crítica, 1984.

LOMAX, Derek W. Rodrigo Jiménez de Rada como Historiador. In: AHI, Actas V, Centro Virtual Cervantes, 1974.

MARTÍN, José-Luis. Alfonso IX y sus relaciones con Castilla. In: Espacio, Tiempo y Forma. Serie III. Historia Medieval, t. 7, 1994. 